\title{
Assessment of Soil Erosion by the RUSLE Model Using Remote Sensing and GIS: A Case Study of Jilin Province of China
}

\author{
Ping ZHOU ${ }^{1}$, Yajin GE ${ }^{1}$, Yue JIANG ${ }^{1}$, Yanan XIE ${ }^{1}$, Zhiwen SI ${ }^{1}$, Hainan YANG ${ }^{1}$, Hong-Yuan \\ HUO $^{2 *}$, Guangyuan $\mathrm{WEI}^{3 *}$, Junchuan $\mathrm{YU}^{4}$, \\ ${ }^{1}$ School of Geosciences and Resources, China University of Geosciences (Beijing), Beijing 100083, China ; \\ zhouping_828@sina.com; 741779109@qq.com; 595872356@qq.com; 1424769980@qq.com; \\ 1034079199@qq.com; 925324145@qq.com; \\ 2 College of architecture and civil engineering, Beijing University of Technology, Beijing 100124, China; \\ huohongyuan@bjut.edu.cn \\ ${ }^{3}$ School of Geosciences, The University of Edinburgh, James Hutton Rd, King's Buildings, Edinburgh EH9 \\ 3FE; 2418990@dundee.ac.uk \\ ${ }^{4}$ China Aero Geophysical Survey and Remote Sensing Center for Natural Resources, Beijing, 10083, China; \\ yujunchuan@mail.cgs.gov.cn \\ * Correspondence: huohongyuanl@bjut.edu.cn; Tel.: (+8618610564621)
}

\begin{abstract}
The accurate assessment and monitoring of soil erosion is of great significance for guiding food production and ensuring ecological security, and it is a current research hotspot. In this paper, remote sensing and geographic information systems (GISs) are combined with the Revised Universal Soil Loss Equation (RUSLE model) to carry out research on soil erosion monitoring and make a quantitative evaluation. According to five factors, including rainfall erosivity, soil erodibility, topography, vegetation cover, crop management and water and soil conservation measures, the distribution of the soil erosion rate in Jilin Province in 2019 was mapped, and the soil erosion rate was divided into 5 levels according to the degree of erosion, including very slight, slight, moderate, severe and extremely severe erosion. Based on the segmented S-slope factor model and the unique topographical features of the study area, the relationships among the soil erosion rate, erosion risk level, erosion area, erosion amount and slope angle $(\theta)$ were systematically analysed, and a slope angle of $15^{\circ}$ was identified as the threshold for soil erosion on sloped farmland in Jilin Province. The total soil erosion in Jilin Province was $402.14 \times 10^{6} t$ in 2019, the average soil erosion rate was $21.6 \mathrm{t} \cdot \mathrm{ha}^{-1} \cdot \mathrm{a}^{-1}$, and the average soil loss thickness was $1.6 \mathrm{~mm} \cdot \mathrm{a}-1$; these values were far greater than the soil erosion rate risk threshold of $10 \mathrm{t} \cdot \mathrm{Ha}^{-1} \cdot \mathrm{a}^{-1}$. Thus, the province has a strong level of soil erosion. We conclude that soil degradation is accelerating, and food production and the ecological environment will face severe challenges. It is suggested that soil erosion control should be carried out according to different types and slopes of land, with an emphasis on the management of forestland and farmland because forestland and farmland are currently the first types of land to be managed in Jilin Province. This paper aims to explore a timely, fast, efficient and convenient soil erosion monitoring and evaluation method and provide effective monitoring tools for agricultural water and soil conservation, ecological safety management and stable food production in Jilin Province and similar black soil areas.
\end{abstract}

Keywords: Soil Erosion Estimation; Quantitative Calculation; RUSLE; Remote Sensing; GIS

\section{Introduction}


Soil erosion is one of the severe scientific problems faced by all countries in the world. Severe soil erosion has caused rapid degradation of the ecological environment $[1,2,3]$. It has adverse influences, such as land degradation, reduced water quality, river sedimentation, road damage and agricultural productivity problems affecting sustainable development $[4,5,6]$. Approximately 75 billion tons of soil is eroded every year worldwide, and most of the world's farmland loses soil at a rate from $13 \mathrm{t} \cdot \mathrm{ha}^{-1} \cdot \mathrm{a}^{-1}$ to $40 \mathrm{t} \cdot \mathrm{ha}^{-1} \cdot \mathrm{a}^{-1}$ [7]. China is one country with serious soil erosion, and the soil erosion area has been as high as 4.92 million $\mathrm{km} 2$, accounting for $51.2 \%$ of the country's total land area [8].

The quantitative evaluation of soil erosion is the key to soil erosion control, and the mathematical evaluation model of soil erosion is an effective tool for evaluating this type of hazard [9]. These applications and models that have been used to estimate the danger of erosion are more accurate and faster than conventional methods [10]. The research field of evaluation models has been constantly innovating for a long time, and the revised universal soil loss equation (RUSLE), which was developed on the basis of the universal soil loss equation (USLE) model, is a classic method $[11,12,13,14,15,16,17]$, as are many other models, such as the Water Erosion Prediction Project (WEPP) [18] and the European Soil Erosion Model (EUROSEM) [19][20].

The final output of the RUSLE model is a distribution map of the soil erosion rate, which is the manifestation of the comprehensive superposition of the distribution maps of five factors, including rainfall erosivity, soil erodibility, topography, vegetation cover and crop management, and water and soil conservation measures $[14,16,21,22,23,24,25,26,27]$. This output is finally used for regional soil erosion risk assessment. Currently, with the development of geographic information systems (GIS) and remote sensing (RS) technology, the analysis and processing of massive spatial data has become feasible, which has promoted the research of traditional soil erosion models. The integration of evaluation models with GIS and RS is a popular and challenging topic of current research [28]. Using statistical methods that combine different soil erosion models with RS data and GIS technology, many studies have been conducted on soil loss in different regions of the world [29-38]. The effective integration of the RUSLE model with RS data and geospatial technology will make the calculations of soil loss in large areas more reliable [39-46].

However, most studies focus only on the discussion of models or model parameters and the classification of regional soil erosion risk grades; meanwhile, there is relatively little use of the model calculation results and actual characteristics of the study area to further analyse the theoretical basis of key factors that cause soil erosion, and few practical protective measures are proposed for the research area. Based on these shortcomings, we used the RUSLE model combined with RS data and GIS technology to carry out soil erosion-related research, analysed the theoretical basis for the key elements of soil erosion in Jilin Province, and proposed practical protective measures. In addition, Jilin Province is located in the middle of the black soil region of Northeast China, the third largest "golden corn belt" in the world. It is China's main food production base and an area that has experienced severe soil erosion for a long time. To better protect this cultivated land, it is necessary to understand the black soil erosion status of Jilin Province as a whole as well as the entire Northeast China region; this aim supports the purpose and significance of this research.

The main purpose of this paper is to explore effective methods for the long-term and rapid monitoring of soil erosion in Jilin Province, China, based on the RUSLE model, RS and GIS technology; additionally, this research provides scientific background data that can be used to improve the protection of black soil. The final results of the research can be used to formulate a decision-making plan for soil erosion prevention and control in Jilin Province, China, and provide a scientific basis for realizing the sustainable development of the social economy in the region.

\section{Study Area}

Jilin Province is located in the middle of the three north-eastern provinces of China, with a total area of approximately 187,400 square kilometres [48]. The topography and geomorphology can be divided into three parts: the eastern mountainous area, the central hills to the Manchuan and Mangang platform, and the western plain area. The terrain is high in the southeast and low in the 
northwest (see Figure 1). The geological conditions in the eastern mountainous areas are complex, and geological disasters such as landslides or mudslides are prone to occur during the rainy season due to the influence of local small fracture structures.

Jilin has a continental monsoon climate in the northern temperate zone. Affected by the difference in topography, rainfall decreases from the southeast to the northwest, and the climate type transitions from a humid climate to a semiarid climate. The average annual rainfall is $605 \mathrm{~mm}$, but the seasonal and regional differences are quite large. Eighty percent of rainfall is concentrated in the summer months of July, August and September, with the most abundant rainfall occurring in the east. The average annual rainfall is greater than $800 \mathrm{~mm}$ [49]. The forest coverage rate is $42.5 \%$, and the grassland area accounts for $11.6 \%$ of the total area. The vegetation shows a clear zonal distribution from the east to west [50].

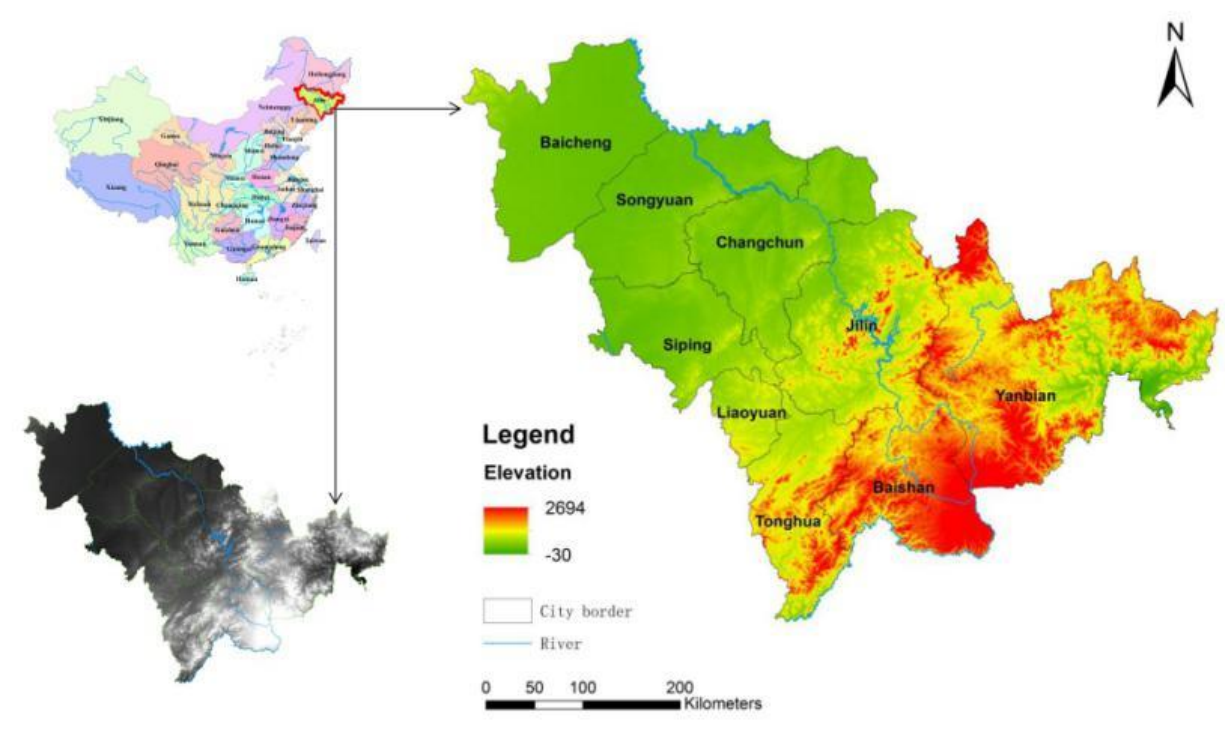

Figure 1. Geographical location and elevation of Jilin Province of China

\section{Materials and Methods}

\subsection{Datasets}

The data used in this paper were all obtained from official data platforms, such as the US NOAA Climate Prediction Center (CPC, http://www.cpc.ncep.noaa.gov/), the United States Geological Survey (USGS), https://earth explorer.usgs.gov/), China's resource and environmental data cloud platform (http://www.resdc.cn), and the Chinese soil dataset of the World Soil Database (HWSD, Harmonized World Soil Database version 1.1) Cold and Arid Regions Science Data Center (http://westdc.westgis.ac.cn) (please see Table 1).

Table 1. The list of datasets used in this paper

\begin{tabular}{|c|c|c|c|}
\hline Data name & Data Sources & Data Usage & Data preprocessing \\
\hline $\begin{array}{l}\text { CMORPH rainfall } \\
\text { data }\end{array}$ & $\begin{array}{l}\text { US NOAA Climate } \\
\text { Prediction Center } \\
\text { CPC }\end{array}$ & $\begin{array}{l}\text { Calculation of } \\
\text { Rainfall } \\
\text { Erosivity Factor }\end{array}$ & $\begin{array}{l}\text { Use IDL programming to read } \\
\text { the data, and use the data } \\
\text { instructions for processing. }\end{array}$ \\
\hline $\begin{array}{l}\text { MODIS vegetation } \\
\text { index data }\end{array}$ & $\begin{array}{l}\text { US Geological } \\
\text { Survey USGS }\end{array}$ & $\begin{array}{l}\text { Acquisition of } \\
\text { vegetation index } \\
\text { and calculation } \\
\text { of vegetation } \\
\text { cover and crop } \\
\text { management } \\
\text { factors }\end{array}$ & $\begin{array}{l}\text { Use the script interface of } \\
\text { MODIS Reprojection Tool (MRT) } \\
\text { to batch process MODIS data } \\
\text { downloaded from UCGS. The } \\
\text { MODIS data is cropped with Jilin } \\
\text { Province vector data, and the }\end{array}$ \\
\hline
\end{tabular}


China Land Use

Classification Map

Administrative division map of Environment Data prefecture-level cities in Jilin Province
China Resources and Cloud Platform

$\begin{array}{lll} & \text { National Qinghai- } & \text { Soil erodibility } \\ \text { China Soil Dataset } & \text { Tibet Plateau Science } & \text { factor } \\ & \text { Data Center } & \text { calculation }\end{array}$

Digital Elevation Geospatial Model data

The vegetation index data for each month is obtained by fusion.

\section{clipping}

template of each

prefecture-level

city in Jilin

Province, the The obtained data is reprojected acquisition of and merged into the land use types administrative division map of and the Jilin Province. calculation of vegetation management factors in Jilin Province

Open the mdb database of HWSD, extract the required 4 parameters, and link with the reprojected raster data of the HWSD data, and crop the soil data of Jilin Province.

Mosaic and reproject the obtained data to obtain DEM data of Jilin Province

\section{Thematic maps}

$>\quad$ The $30 \mathrm{~m}$ spatial resolution digital elevation map of Jilin Province was obtained from the space shuttle radar topography survey data provided by NASA (SRTM, Shuttle Radar Topography Mission) (see Figure 1);

$>\quad$ The land-use type map of Jilin Province (LUCC land use/cover change) with a spatial resolution of $30 \mathrm{~m}$ in 2018 was created using Landsat8 as a base map (see Figure 2).

$>\quad$ The soil type map of Jilin Province was created (see Figure 3).

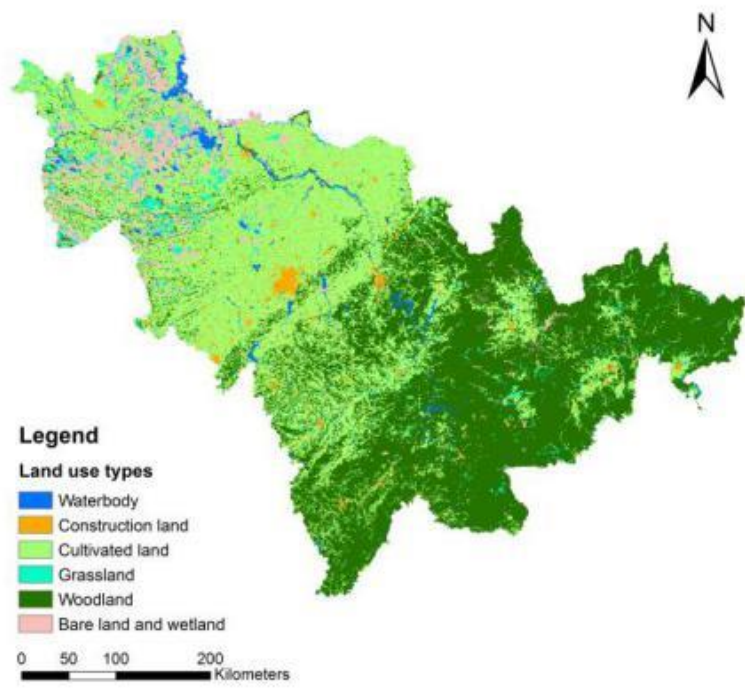

Figure 2. Land-use types in Jilin Province 


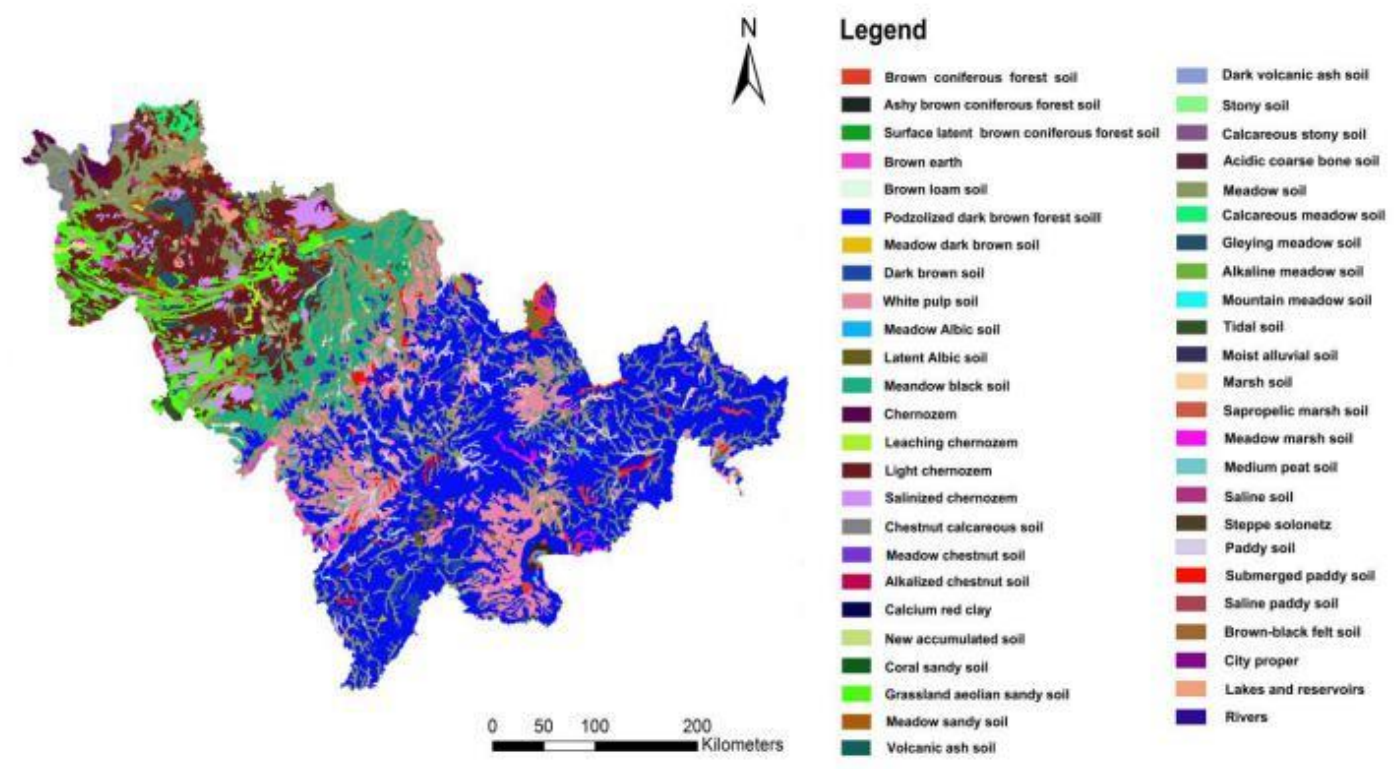

Figure 3. Soil types in Jilin Province

\subsection{Methodology}

This study used the RUSLE model combined with RS and GIS technology to assess the status of soil erosion in Jilin Province, China. First, the RS data, geographic data, and soil data related to the study area were collected and analysed. Second, the distribution results of the five soil factors (R, LS, $\mathrm{K}, \mathrm{C}$, and P) of the RUSLE model were calculated. Third, the soil erosion rate distribution result map of Jilin Province in 2019 was obtained based on the RUSLE model, and the soil water and soil losses in Jilin Province were divided into 5 levels. Finally, in terms of terrain slope angle, administrative divisions and land-use types, the soil erosion status and causes in Jilin Province were quantitatively assessed and analysed, and reasonable suggestions for soil erosion control were given. The detailed flowchart is shown in Figure 4. 


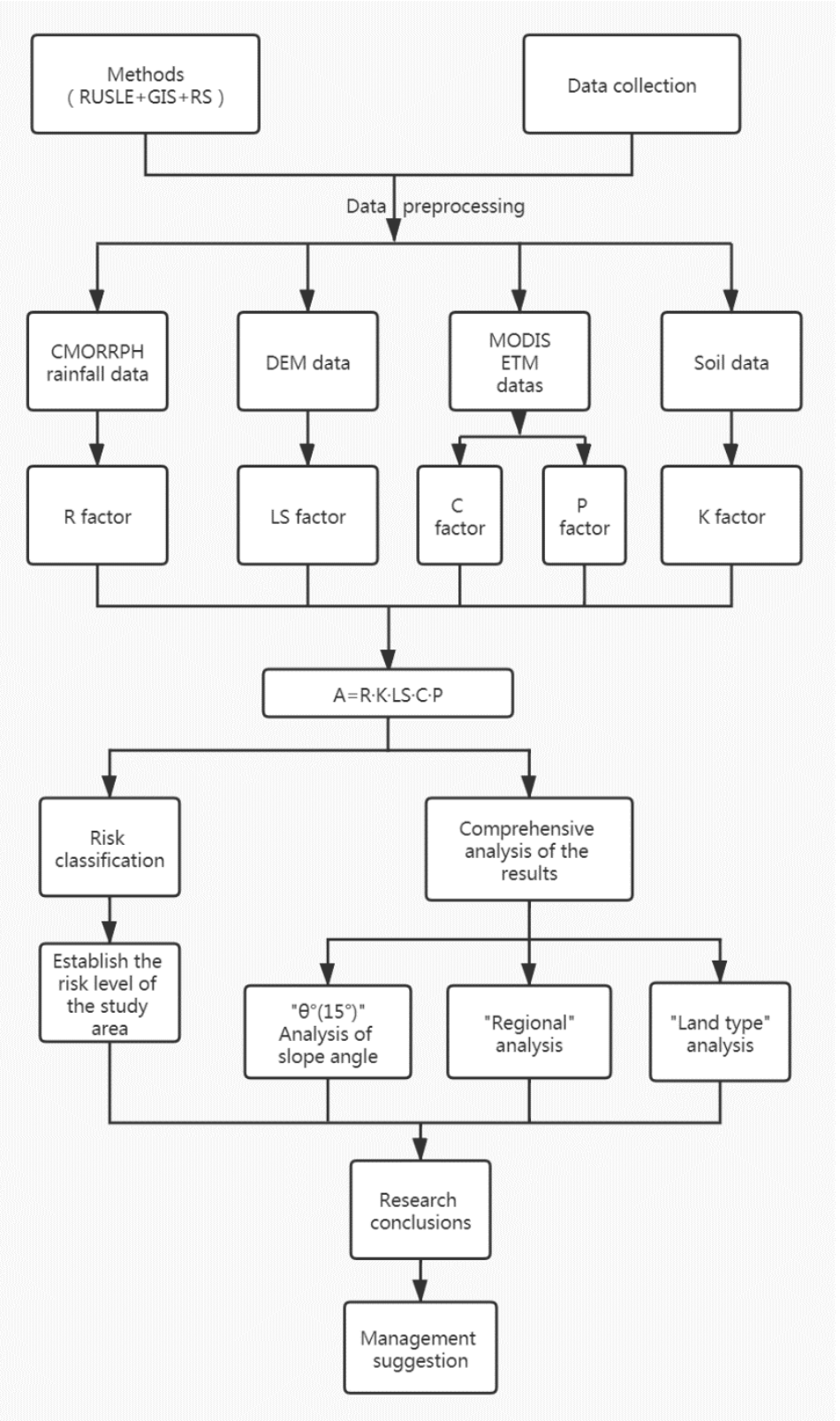

Figure 4. The flowchart of the study

\subsubsection{RUSLE model structure and parameter estimation}

The RUSLE model is a revised model officially implemented and promulgated by the United States Department of Agriculture [15,16]. Although it was originally developed for agricultural land, it is now widely used in non-agricultural land at different spatial scales [26]. The model calculation of Formula (1) is as follows:

$$
A=R \cdot K \cdot L S \cdot C \cdot P
$$

where $A$ is the annual average soil erosion rate factor ( $t \cdot$ ha-1 $\cdot a-1), R$ is the rainfall erosivity factor $\left(\mathrm{MJ} \cdot \mathrm{mm} \cdot \mathrm{ha}^{-1} \cdot \mathrm{h}^{-1} \cdot \mathrm{a}^{-1}\right), \mathrm{K}$ is the soil erodibility factor $\left(\mathrm{t} \cdot \mathrm{ha}^{-1} \cdot \mathrm{h}^{-1} \cdot \mathrm{MJ}^{-1} \mathrm{~mm}^{-1}\right), \mathrm{LS}$ is the slope-steepness factor (dimensionless), $\mathrm{C}$ is the crop management factor (dimensionless, ranging between 0 and 1 ), and $\mathrm{P}$ is the conservation support practice (dimensionless, ranging between 0 and 1) [16].

3.2.2 Rainfall erosivity factor $(\mathrm{R})$ 
The rainfall erosivity factor $(\mathrm{R})$ is the product of rainfall kinetic energy and the maximum 30minute rainfall intensity $[15,16,51]$. In this study, the calculation in Formula (2) was applied for black land in Northeast China, as proposed by Zhang et al. [14, 52]:

$$
\mathrm{R}=\Sigma \mathrm{Ri}=\Sigma\left(\mathrm{E}_{60} \mathrm{I}_{30}\right)
$$

where $\mathrm{Ri}$ is the rainfall erosivity per unit area $\left(\mathrm{MJ} \cdot \mathrm{mm} \cdot \mathrm{ha}^{-1} \cdot \mathrm{h}^{-1} \cdot \mathrm{a}-1\right)$, I30 is the maximum rainfall intensity after 30 minutes of rainfall $\left(\mathrm{mm} \cdot \mathrm{h}^{-1}\right), \mathrm{E} 60$ is the rainfall kinetic energy per unit area after 60 minutes, and $\mathrm{E}$ is obtained through the calculation formula of the RUSLE model (3) as follows:

$$
\mathrm{E}=\left[0.29-0.2088 \exp \left(-0.082 i_{\text {avr }}\right)\right] \cdot \Delta \mathrm{V}
$$

where $i_{\text {avr }}$ is the rainfall erosivity (Ri) calculated every 60 minutes. After accumulating and summing, the rainfall erosivity of one year is calculated, and $\Delta \mathrm{V}$ is the rainfall $(\mathrm{mm})$. Considering the highest accuracy in estimating the erosivity of a single rainfall event, the 60-minute rainfall kinetic energy $€$ and the 30-minute maximum rainfall intensity (I) can obtain the highest accuracy; in this paper, CMORPH radar data were used to obtain the rainfall in Jilin Province $[53,54,55]$.

Currently, the use of microwave and infrared RS data with high spatial and temporal resolutions to obtain regional rainfall are very mature and effective technical tools, and they have been widely used in many applications, such as climate and soil erosion monitoring [56,57,58,59,60]. Compared with obtaining rainfall based on limited ground station data, this method has great advantages in both temporal resolution and spatial resolution [61,62]. Hourly rainfall data $(\mathrm{mm} \cdot \mathrm{h}-1)$ are stored in the form of a multidimensional array for CMORPH. Regarding these data, the first 30 minutes of rainfall data are stored in the first band, and the data of the last 30 minutes are stored in the second band. Therefore, there are 24 files of rainfall data in one day, and the amount of data in a year reaches 8784. Thus, it is necessary to perform batch processing of CMORPH rainfall data $[63,64,65]$.

In this paper, the global annual rainfall in 2019 was retrieved from CMORPH radar data, and the batch processing of the data was implemented based on IDL language programming. Through the cropping of RS data from the study area and based on the R model, the image of R is obtained (see Figure 5-(a)). The range of rainfall erosivity in Jilin Province in 2019 was between 262.626 and 4520.18 MJ.mm/(ha-1.h.a). High-value areas of R appeared in Siping, Liaoyuan, Jilin and Yanbian city, and $\mathrm{R}$ had a certain relationship with the frequent occurrence of heavy rains in summer in these areas.

\subsubsection{Soil erodibility factor $(\mathrm{K})$}

The soil erodibility factor $(\mathrm{K})$ is an index used to evaluate the degree of soil rainfall erosivity separation, erosion, and ease of transportation; thus, it reflects the change in soil under the action of each unit of external energy force $[16,66]$. In this paper, the quantitative statistical model EPIC (Erosion-Productivity Impact Calculator) proposed by Williams et al. was used to estimate the $\mathrm{K}$, as expressed by Formula (4):

$$
K=\left\{0.2+0.3 \exp \left[-0.0256 S_{a}\left(1-\frac{S_{i}}{100}\right)\right]\right\}\left[\frac{S_{i}}{C_{i}+S_{i}}\right]^{0.3}\left[1-\frac{0.25 C}{C+\exp \left(3.72-2.95 S_{n}\right)}\right]\left[1-\frac{0.7 S_{n}}{S_{n}+\exp \left(-5.51+22.9 S_{n}\right)}\right]
$$

where $S_{n}=1-S_{a} / 100, S_{a}$ is the sand content, \%, $S_{i}$ is the silt content, \%, $C_{i}$ is the clay content, \%, and $C$ is the organic carbon content, \%. The T_SAND, T_SILT, T_CLAY and T_OC fields were extracted from the HWSD soil database and brought into Formula (4) to calculate the K factor of Jilin Province [68].

Based on Figure 5-(b), the K of Jilin Province ranges from 0.1005 to $0.3481 \mathrm{t} \cdot \mathrm{ha} \cdot \mathrm{h} /(\mathrm{ha} \cdot \mathrm{MJ} \cdot \mathrm{mm})$. The western part of the study area is dominated by grassland aeolian sandy soil, stony soil and chernozem, with textures ranging from gravel to coarse sand, relatively small $\mathrm{K}$ values, and weak soil water erosion abilities. The central part is the main black soil grain-producing area, with fine soil textures, low $\mathrm{K}$ values, and weak soil water erosion abilities. The eastern mountainous area is dominated by dark brown soil and albic soil, with medium textures, mostly coarse silt, high $\mathrm{K}$ values, and strong soil erosion abilities. 


\subsubsection{Topographic factor (LS)}

The slope length and slope steepness factor (LS) is divided into two parts, where $L$ is the slope length factor and $S$ is the slope steepness factor. LS represents, with other conditions remaining unchanged, the ratio of the amount of soil loss on the slope of a given slope length and slope steepness to the amount of soil loss on the typical slope of a standard runoff plot [14].

Based on the LS factor model theory developed by Wischmeier and Smith [69,70,71], and referring to the segmented topographic factor model proposed by Liu et al. [72], the L and S factor equations of Jilin Province were established, and the slope length factor L in Formula (5) is as follows:

$$
\mathrm{L}=(\lambda / 22.1)^{m}
$$

where $\lambda$ is the wavelength, $m$ is the factor that varies with the slope steepness $\theta$, if $\theta \leq 1^{\circ}, m=0.2$, and if $1^{\circ}<\theta \leq 3^{\circ}, \mathrm{m}=0.3$, and if $3^{\circ}<\theta \leq 5^{\circ}, \mathrm{m}=0.4$, and if $\theta>5^{\circ}, \mathrm{m}=0.5$. The slope steepness factor $\mathrm{L}$ is shown in Formula (6) as follows:

$$
S=\left\{\begin{array}{cc}
8.661 \times \sin \theta+0.331, & 0 \leq \theta \leq 5^{0} \\
20.492 \times \sin \theta+0.6, & 5^{0} \leq \theta \leq 15^{0} \\
19.347 \times \sin \theta-0.028, & 15^{0} \leq \theta \leq 25^{0} \\
20.223 \times \sin \theta-0.308, & 25^{0} \leq \theta \leq 35^{0} \\
17.635 \times \sin \theta+1.224, & \geq 35^{0}
\end{array}\right.
$$

where $\theta$ is the slope angle. Here, the $S$-factor model uses a five-degree increase in $\theta$ as a segmented interval and establishes regression analysis equations for the slope factor $S$ in different intervals to determine the generation of equation coefficients. In this way, it can only be suitable for Jilin Province of China, and it can also highlight the characteristics of soil water erosion in Jilin Province.

Using the 30-m DEM data obtained by the SRTM (see Figure 1), the $S$ and L factors were extracted based on the ArcGIS 10.2 platform, and the final distribution of the LS factor of the study area was obtained through a series of data conversions, as shown in Figure 5-(c). The study found that most of the high-intensity erosion grades in Jilin Province were distributed in the eastern mountainous areas, which further proved that the degree of soil loss increased with the slope angle faster than with the slope length $[14,70,73]$.

\subsubsection{Cropping management factor $(\mathrm{C})$}

The index factor $C$ (cover-management factor), which measures vegetation coverage and management, has a good inhibitory effect on soil erosion. $C$ is, when the conditions of other factors are controlled, the ratio of the amount of soil loss under a specific crop or vegetation cover to the amount of loss of continuous fallow land after cultivation $[15,16]$. In this paper, using the relationship equation between the $C$ factor and vegetation coverage proposed by Cai et al. [74], which is applicable to the geographical features of Jilin Province, the specific formula is shown in Formula (7):

$$
\left\{\begin{array}{ccrl}
C & =1 & V=0 \\
C=0.6508-0.34361 \cdot \lg & 0 \leq V \leq 78.3 \% \\
C=0 & V \geq 78.3 \%
\end{array}\right.
$$

From Formula (7), when the vegetation coverage $V>78.3 \%$, the $C$ value is 0 , that is, there is no soil loss; when the vegetation coverage $V \approx 0$, the $C$ value is close to 1 , indicating significant soil loss. Generally, the vegetation coverage is $0 \leq \mathrm{V} \leq 78.3 \%$, and the meaning is set as the annual average vegetation coverage. In this study, the combination of the vegetation coverage $\mathrm{V}$ value and the land use value was used to estimate the annual average $C$ factor. The results are shown in Table 1 , and the $\mathrm{C}$ factor value was directly assigned to the land-use map. The $\mathrm{C}$ factor distribution is shown in Figure $5-(d)$. 
In above equation (7), the determination of the $\mathrm{V}$ value is based on the pixel dichotomy model of the MODIS NDVI data and used to calculate the average annual vegetation coverage V from January to December in the 2019 image. The specific formula is as expressed by Formula (8):

$$
V=\frac{\left(N D V I-N D V I_{\text {soil }}\right)}{\left(N D V I_{\text {veg }}-N D V I_{\text {soil }}\right)}
$$

\subsubsection{Conservation practice factor $(\mathrm{P})$}

The water and soil conservation measure factor $\mathrm{P}$ (support practice factor) is the most difficult parameter to determine in the RUSLE model, and its value is often different from place to place [16]. This study refers to the "General Soil Loss Equation Manual" issued by the U.S. Department of Agriculture No. 537 Agricultural Manual, combined with field investigations and the data collected by Zhang [75] from multiple experiments in Heilongjiang Province, to obtain information on the C and $\mathrm{P}$ values of different land-use types in Jilin Province, as shown in Table 1:

Table 1. The $C$ and $P$ values of different land-use types in Jilin Province, China

\begin{tabular}{|c|c|c|c|c|c|c|}
\hline Land using types & $\begin{array}{c}\text { Cultivated } \\
\text { land }\end{array}$ & $\begin{array}{c}\text { Woodl } \\
\text { and }\end{array}$ & Bare land & $\begin{array}{c}\text { Grassla } \\
\text { nd }\end{array}$ & $\begin{array}{c}\text { Constructio } \\
\text { n land }\end{array}$ & Wetlands \\
\hline Annual average $\mathrm{V} \%$ & 10 & 75 & 50 & 70 & 20 & 25 \\
\hline C value & 0.31 & 0.006 & 0.06 & 0.017 & 0.2 & 0.18 \\
\hline$P$ value & 0.45 & 0.9 & 1 & 0.55 & 0.25 & 1 \\
\hline
\end{tabular}

\section{Results and Discussion}

\subsection{Mapping the RUSLE model factors of Jilin Province in China}

To obtain the spatial variation in the abovementioned characteristic values for all of Jilin Province, the values must be unified into the same geographic coordinates to calculate the amount of soil loss. In this study, each factor was reprojected and resampled to obtain a raster image with the coordinates of WGS84 (World Geodetic System 1984) and a resolution of $30 \mathrm{~m} \times 30 \mathrm{~m}$. Based on the ArcGIS platform, the five obtained factors were integrated and quantified, and finally, the spatial distribution map of the soil erosion rate in Jilin Province was generated and mapped, as shown in Figure 5-(f). 
(a)

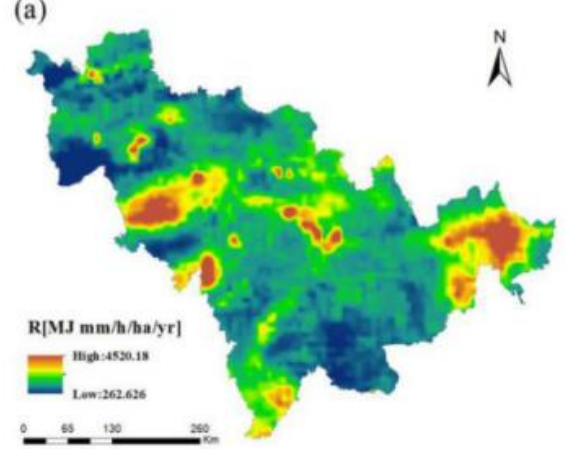

(c)

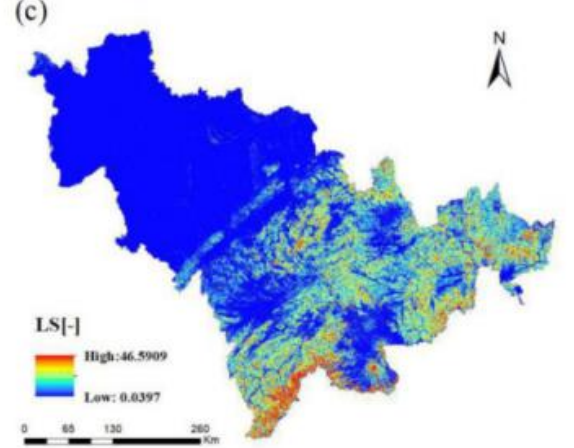

(b)

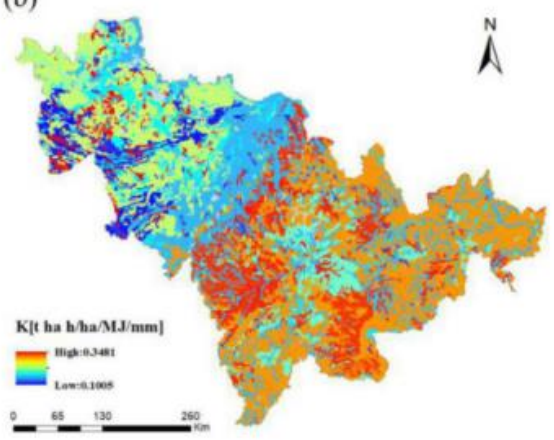

(d)

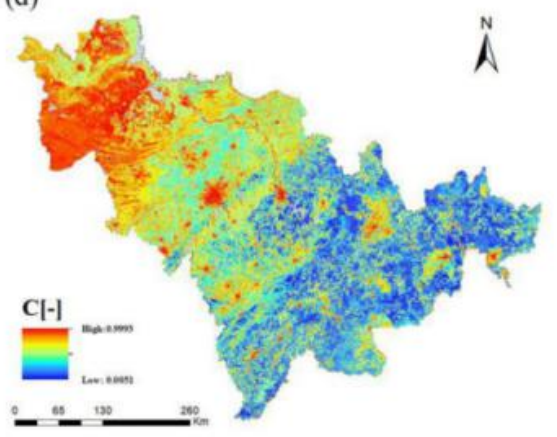

(f)

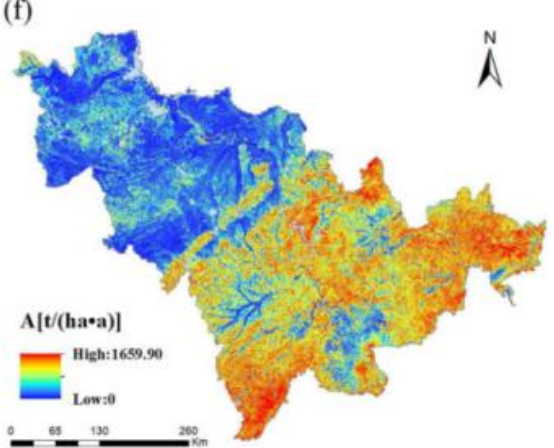

Figure 5. Maps of the Revised Universal Soil Loss Equation (RUSLE) factors of Jilin Province in China: (a)

$\mathrm{R}$, the rainfall-runoff erosivity factor; (b) K, the soil erodibility factor; (c) LS, the slope length and steepness factor; (d) C, the cover fraction factor; (e) P, the support practice factor; (f) the annual average of the soil erosion rate factor.

\subsection{Classification of the soil erosion risk}

According to the results of the soil erosion rate distribution map of Jilin Province in 2019, referring to the soil risk classification assessment method of Singh et al. (1992) [76], and considering the difference in the division of the soil erosion risk levels of different spatial scales (global scale, national scale, and regional scale) [77], this paper divided the soil erosion risk level of Jilin Province into five levels (see Figure 5): very slight $\left(<5 \mathrm{t} \cdot \mathrm{ha}^{-1} \cdot \mathrm{a}^{-1}\right)$, slight $\left(5-10 \mathrm{t} \cdot \mathrm{ha}^{-1} \cdot \mathrm{a}^{-1}\right)$, moderate $\left(10-20 \mathrm{t} \cdot \mathrm{ha}^{-1} \cdot \mathrm{a}^{-}\right.$ $\left.{ }^{1}\right)$, severe $\left(20-40 \mathrm{t} \cdot h \mathrm{~h}^{-1} \cdot \mathrm{a}^{-1}\right)$, and extremely severe $\left(>40 \mathrm{t} \cdot \mathrm{ha}^{-1} \cdot \mathrm{a}^{-1}\right)$.

Figure 6 shows that the water erosion situation in Jilin Province is distributed regularly, with moderate erosion, severe erosion, and extremely severe erosion mostly concentrated in the mountainous areas in the east and in the transitional belts of low mountains and hills in the middle and east. Due to abundant precipitation throughout the year in 2019, as the altitude increased from west to east, the soil erosion in this area increased when extreme weather occurred. Very slight erosion and slight erosion were mostly distributed in the Manchuan and Mangangtai areas in the middle and alluvial plains in the western valley, while the valleys and low-lying areas in the eastern mountainous areas were also distributed in small areas. In addition, due to the high population 
density and the long-term impact of human activities at low altitudes, as the vegetation coverage decreased, soil erosion increased accordingly.

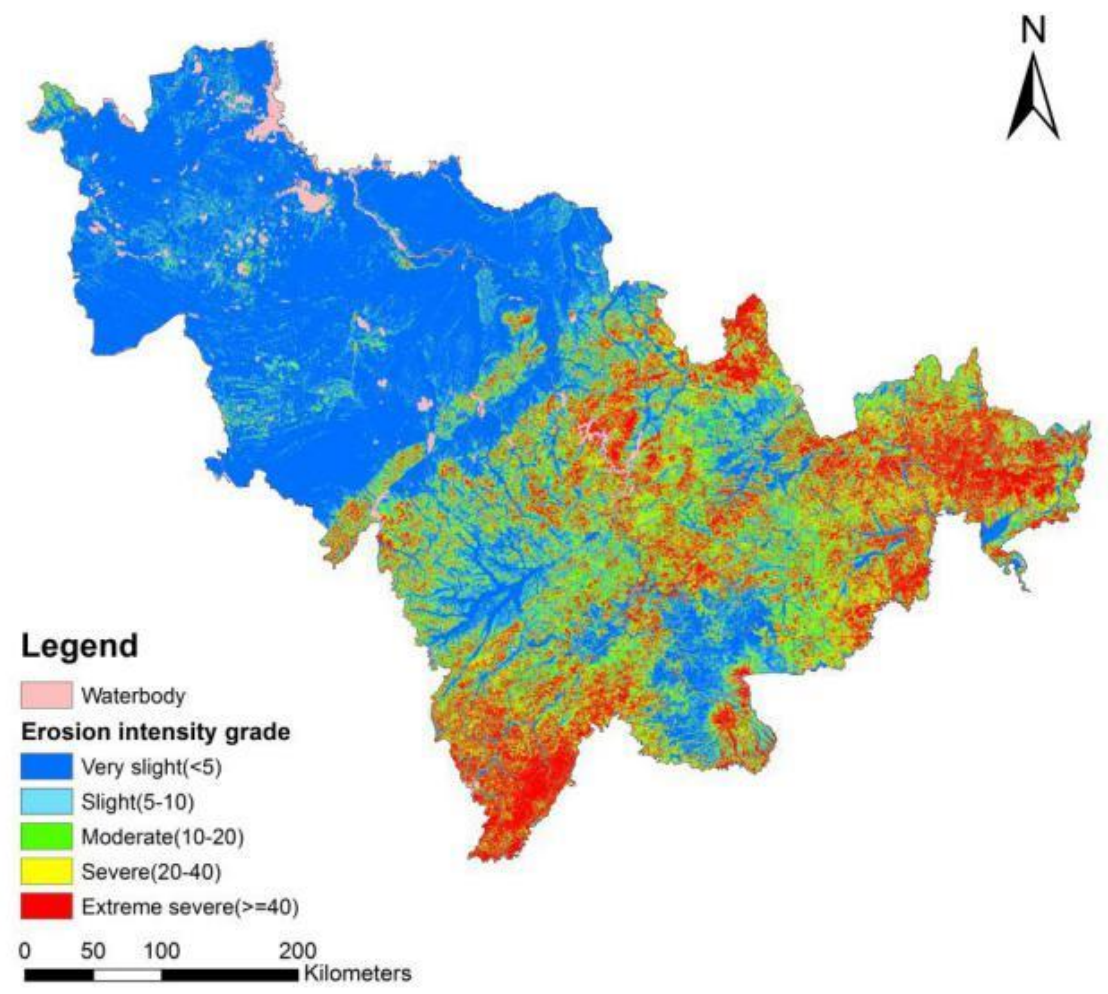

Figure 6. Classification of soil erosion risk levels in Jilin Province, China

\subsection{Overall analysis of soil erosion risk in Jilin Province}

According to calculations, the average soil erosion rate of Jilin Province is $21.6 \mathrm{t}^{-} \mathrm{ha}^{-1} \cdot \mathrm{a}^{-1}$, which is equivalent to removing $1.6 \mathrm{~mm}$ of topsoil from the province each year. Table 2 shows that the soil erosion risk level in Jilin Province in 2019 was severe. Morgan [78] proposed an average annual soil loss of 10 tons per hectare as the threshold value for the sustainable development of ecological agriculture. This study shows that the current land ecological environment in Jilin Province is at a higher risk, and the situation is not optimistic.

Table 2 shows that $58.89 \%$ of the area is in the low-risk category, which seems to indicate that the overall ecological environment of Jilin Province is good, and the proportion of severe and extremely severe soil erosion levels is only $28.59 \%$, which is less than $1 / 3$ of the total area. However, the total amount of erosion is as high as $336.799 \times 10^{6} \mathrm{t}$, which significantly increases the risk of soil erosion in Jilin Province.

Table 2. Classification of soil erosion risk using the soil erosion rate in Jilin Province of China, 2019

\begin{tabular}{ccccc}
\hline $\begin{array}{c}\text { Soil erosion rate } \\
\left(\mathbf{t ~ h a}^{-\mathbf{1}} \mathbf{a}^{-\mathbf{1}}\right)\end{array}$ & Soil erosion risk & $\begin{array}{c}\text { Soil loss thickness } \\
\left(\mathrm{mm} \cdot \mathbf{a}^{-1}\right)\end{array}$ & $\begin{array}{c}\text { Soil erosion amount } \\
(\mathbf{1 0} \mathbf{5})\end{array}$ & $\begin{array}{c}\text { Total area } \\
(\%)\end{array}$ \\
\hline$<5$ & Very slight & 0.14 & 161.91 & 47.51 \\
$5-10$ & Slight & 0.53 & 151.24 & 11.38 \\
$10-20$ & Moderate & 1.08 & 340.27 & 12.51 \\
$20-40$ & Severe & 2.11 & 680.50 & 12.83 \\
$>40$ & Extremely severe & 6.80 & 2687.49 & 15.76 \\
Total & & & 4021.40 & 100 \\
\hline
\end{tabular}


From the perspective of administrative division, Tonghua city is the most susceptible area to erosion, with a soil erosion rate of $47.38 \mathrm{t} \cdot \mathrm{ha}^{-1} \cdot \mathrm{a}^{-1}$, followed by Yanbian, Baishan, Jilin, and Liaoyuan (see Table 3). The proportion of severe and extremely severe soil erosion levels in these 5 cities was also much higher than that of other regions (see Figure 7). These 5 cities are located in the eastern mountainous area of Jilin Province or in the transitional zone from low mountains to hills (see Figure 1). They are obviously affected by topography and extreme weather. In addition, the mining industry is relatively highly developed, and many more scenic spots are distributed in these cities; thus, soil erosion has a certain relationship with the excessive reclamation of steeply sloped farmland, the improper development of mining resources, the tourism industry, and villa areas [79].

The four prefecture-level administrative regions of Changchun, Siping, Baicheng, and Songyuan in the middle and west of Jilin Province are areas with slight water erosion (see Table 3), especially in Baicheng and Songyuan, because they are close to the Horqin grassland in Inner Mongolia, China. Soil wind erosion plays a major role, and soil water erosion is relatively low. The soil erosion here is closely related to land desertification, low vegetation coverage and improper management. This region is also the most vulnerable area in terms of natural ecology in Jilin Province, and it is necessary to adjust the regional industrial structure.

Table 3. Statistics on soil erosion for all jurisdictions in Jilin Province

\begin{tabular}{|c|c|c|c|c|}
\hline City & $\begin{array}{c}\text { City area } \\
10^{4} \mathrm{ha}\end{array}$ & $\begin{array}{l}\text { Soil erosion amount } \\
\qquad 10^{5} t\end{array}$ & $\begin{array}{c}\text { Soil erosion rate } \\
\qquad /(\mathbf{h a} \cdot \mathbf{a})\end{array}$ & Soil erosion risk \\
\hline Baicheng & 24.03 & 61.84 & 2.57 & Very slight \\
\hline Songyuan & 20.03 & 44.61 & 2.23 & Very slight \\
\hline Changchun & 20.07 & 97.90 & 4.88 & Very slight \\
\hline Siping & 14.12 & 98.32 & 6.97 & Slight \\
\hline Liaoyuan & 5.07 & 97.80 & 19.31 & Moderate \\
\hline Jilin & 27.05 & 718.03 & 26.54 & Severe \\
\hline Tonghua & 15.34 & 726.63 & 47.38 & Extremely severe \\
\hline Baishan & 17.27 & 469.69 & 27.20 & Severe \\
\hline Yanbian & 42.87 & 1706.08 & 39.79 & Severe \\
\hline
\end{tabular}

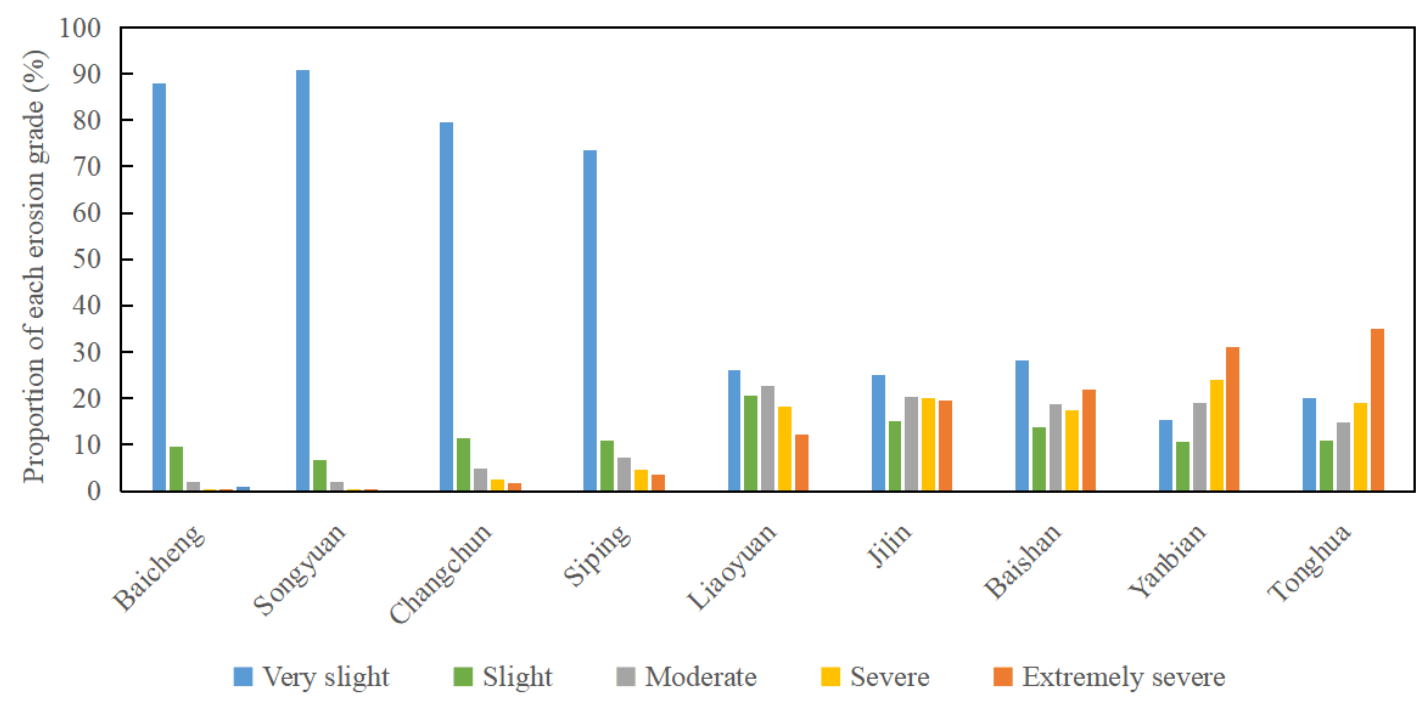

Figure 7. The proportion distribution of risk level in the administrative regions of Jilin Province of China 


\subsection{Analysis of soil erosion characteristics with increasing slope angle $\theta$}

Based on the established segmented S-slope factor model, this study divides the slope angle $\theta$ into eight intervals, including $0^{\circ} \sim 5^{\circ}, 5^{\circ} \sim 10^{\circ}, 10^{\circ} \sim 15^{\circ}, 15^{\circ} \sim 20^{\circ}, 20^{\circ} \sim 25^{\circ}, 25^{\circ} \sim 30^{\circ}, 30^{\circ} \sim 35^{\circ}$, and $>35^{\circ}$. Then, the characteristics of soil erosion in the study area are discussed. First, the soil erosion rate increases stepwise with increasing slope angle $\theta$ (see Figure 8-(a)), indicating that the $S$ accelerates soil erosion [13]. Second, with the increase in the slope angle $\theta$, the soil erosion risk level tends to be significantly strengthened. When the slope angle $\theta$ reaches approximately $15^{\circ}$, the areas with strong and extremely strong erosion risk levels increase sharply, while the areas with slight erosion risk decrease sharply (see Figure 8-(b)). Third, the soil erosion area decreases with the increase in the slope angle $\theta$, and the erosion area decreases sharply when the slope angle is approximately $15^{\circ}$, while the total soil erosion reaches the peak when the slope angle $\theta$ is approximately $15^{\circ}$ (see Figure 8-(c), Figure 8-(d)), which shows that the territory of Jilin Province is experiencing high-intensity soil erosion in areas with a slope angle of approximately $15^{\circ}$, and these areas are in urgent need of treatment.
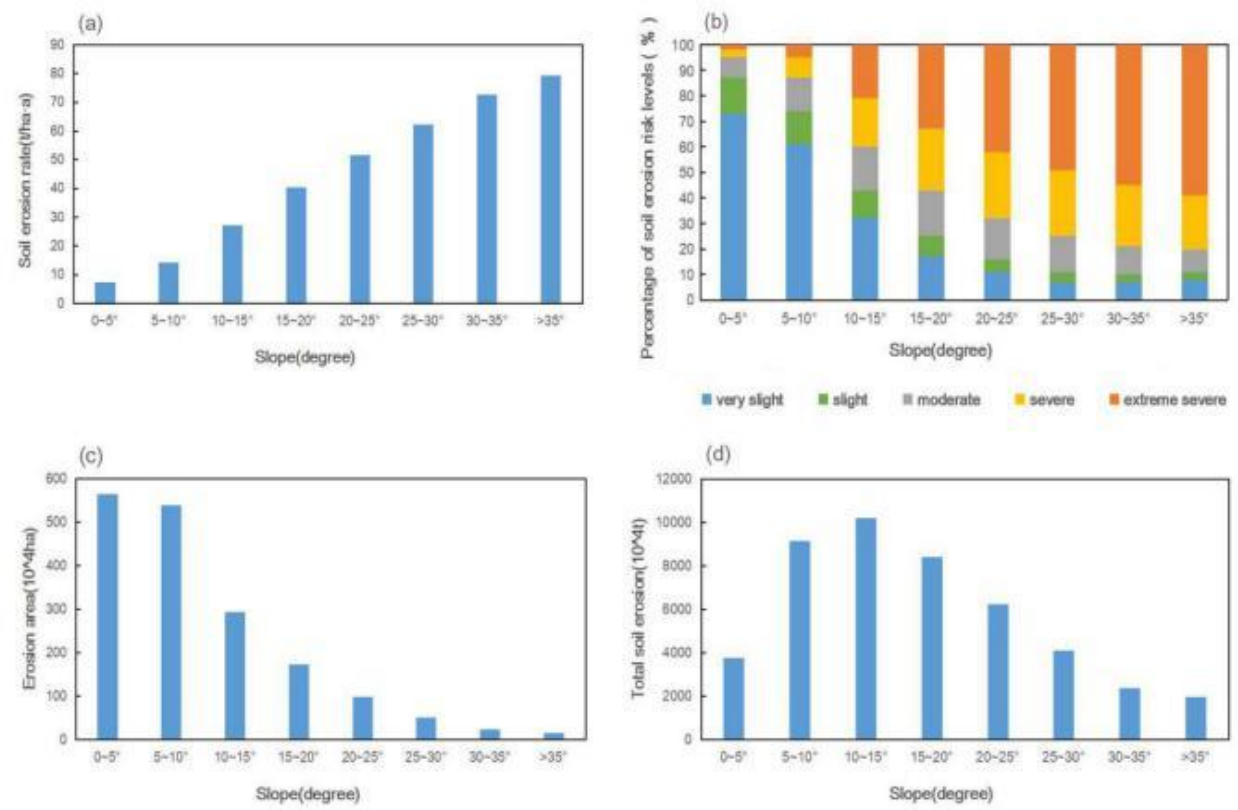

Figure 8. Analysis of the different characteristics of soil erosion with slope angle $\theta$ in Jilin Province. (a) Change trend graph of soil erosion rate with slope angle $\theta$; (b) Change trend graph of soil erosion risk with slope angle $\theta$; (c) Change trend graph of soil erosion area with slope angle $\theta$; (d) Trend map of total soil erosion changes with slope angle $\theta$.

\subsection{Analysis of farmland management in different intervals with slope angle $\theta$}

According to the different intervals of the slope angle $\theta$, the agricultural land in Jilin Province is divided into three parts (see Figure 9): sloped farmland with a slope angle of $0^{\circ} \leq \theta \leq 5^{\circ}$, sloped farmland with a slope angle of $5^{\circ} \leq \theta \leq 15^{\circ}$, and sloped farmland with steep slopes with a slope angle $\theta \geq 15^{\circ}$. Based on the ArcGIS 10.2 platform, the area of each of these three parts of farmland of the study area was extracted for statistical analysis. First, statistics show that the area of gently sloping farmland with a slope angle of $0^{\circ} \leq \theta \leq 5^{\circ}$ is $674.95 \times 10^{4}$ ha. This part of farmland accounts for the largest proportion, approximately $88.32 \%$ of the total arable land, and it is mainly distributed in Songyuan and Baicheng (western Jilin Province), Changchun city and Siping city (middle area of Jilin Province), and low-lying areas such as Liaoyuan and Tonghua in the eastern mountainous area of Jilin Province. It is suggested that this part of the cultivated land should mainly adopt farming methods such as crop rotation and mixed cropping to preserve moisture and fertilizer. Second, the area of sloped farmland with a slope angle of $5^{\circ} \leq \theta \leq 15^{\circ}$ is $79.14 \times 10^{4}$ ha, accounting for $10.36 \%$ of the total farmland area. This area is mainly distributed in eastern Changchun city and Siping city and 
western Yuan city, Tonghua city and Jilin city. It is recommended to adopt farming methods such as cross-slope farming, contour ridge farming and terrace construction to control the occurrence of soil erosion. Third, the area of farmland with steep slopes with a slope angle of $\theta \geq 15^{\circ}$ is $10.1 \times 10^{4}$ ha, accounting for $1.32 \%$ of the total arable land. This part of agricultural land accounts for a small proportion and is scattered in various areas in the eastern mountainous area of Jilin Province. It is recommended to adopt the plan of "returning farmland to forest and grassland" to improve the regional ecological environment, and from an economic perspective, the planting of economic forests is encouraged.

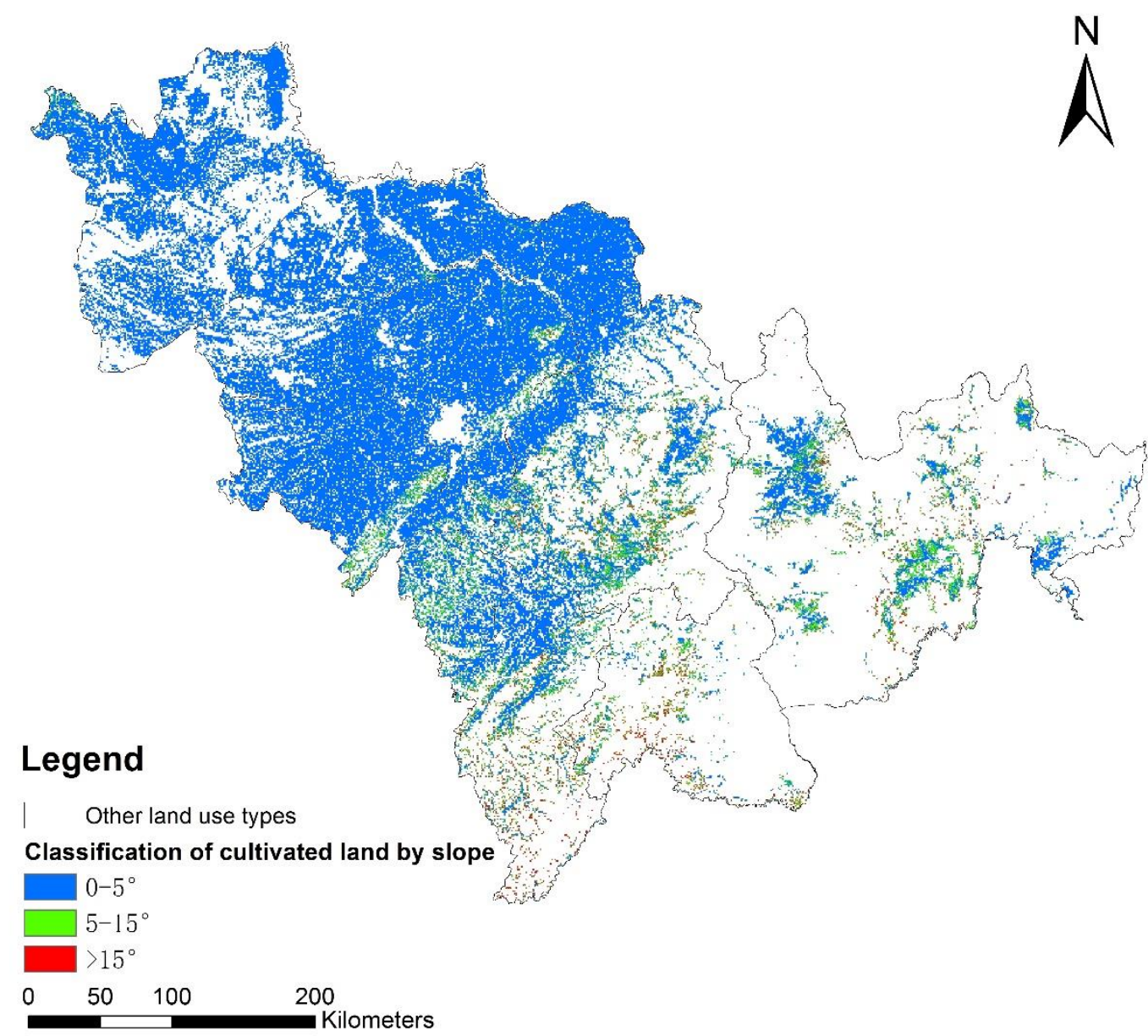

Figure 9. Distribution of farmland in different intervals with slope angle $\theta$

\subsection{Analysis of soil erosion characteristics of different land-use types}

The scientific management of land-use types is the key to preventing soil erosion [80]. At present, there are six types of land use in Jilin Province (see Figure 10). The analysis shows that forestland is the land type with the highest erosion risk level, and the soil erosion rate reaches $84.12 \mathrm{t} \cdot \mathrm{ha}^{-1} \cdot \mathrm{a}^{-1}$, which represents an extremely severe soil erosion level (see Figure 11(a)). Forestland in Jilin Province is mainly distributed in the eastern mountainous area. Although the vegetation coverage is high, there are many ridges and valleys, as well as much erosive rainfall. In addition, illegal deforestation and tree theft occur occasionally [81], which can cause a greater area to have a high risk of soil erosion (Figure 11(b)). Therefore, it is urgent to strengthen forest protection. Regarding farmland, although its erosion level is not high, its coverage is wide, and the total amount of soil erosion is very high. Since farmland is mainly distributed in the central and western plains and plateau areas and the lowlying areas of the eastern middle and low mountainous regions, it is the main black-soil-grainproducing area in Jilin Province. The population density here is high, and improper crop 
management has increased the rate of soil degradation. Therefore, managing these two types of land is the focus of future ecological protection work in Jilin Province [82].

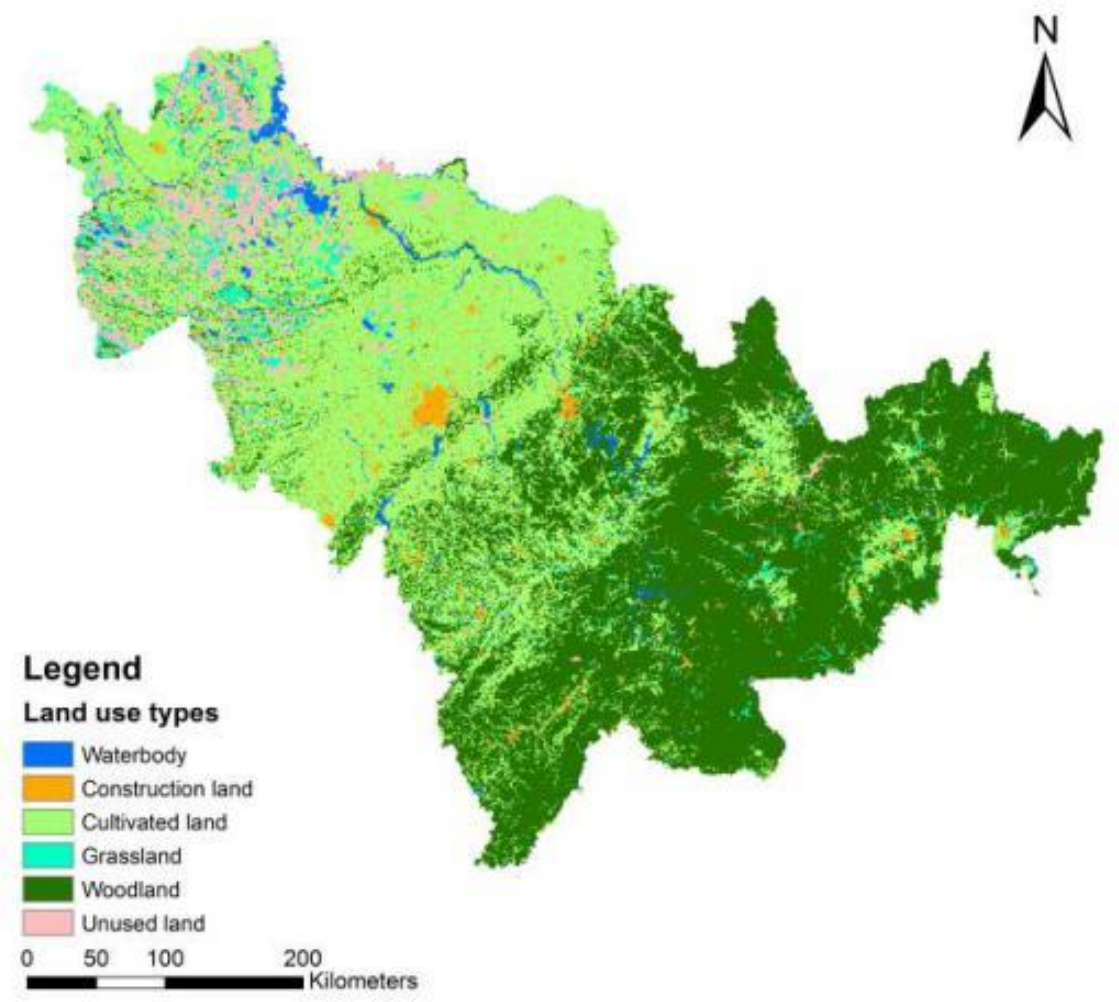

Figure 10. Land-use type map of Jilin Province, China

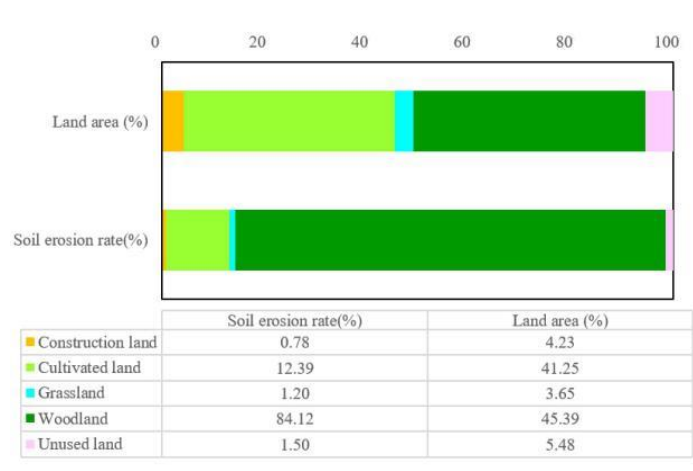

(a)

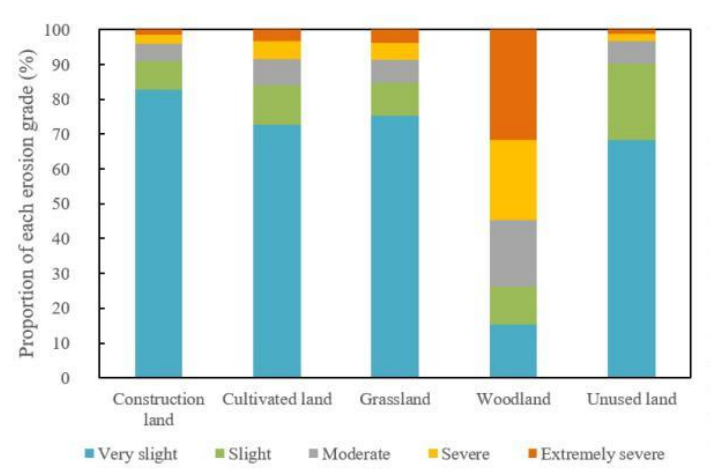

(b)

Figure 11(a) shows the statistics of erosion rate and erosion area of different land-use types, and Figure 11(b) shows the proportions of erosion risk levels in different land-use types.

\section{Conclusions}

This paper uses the improved RUSLE model, RS, GIS and other technologies and uses Jilin Province as the research area; the research area was divided into 5 soil erosion risk levels (very slight, slight, moderate, severe and extremely severe), and we achieved the following innovative results.

(1) Basic soil erosion data were obtained in Jilin Province, and the total soil erosion in Jilin Province in 2019 was $4021.40 \times 105 \mathrm{t}$, the average soil erosion rate was $21.6 \cdot \mathrm{ha}^{-1} \mathrm{a}^{-1}$, the average loss thickness was $1.6 \mathrm{~mm} \cdot \mathrm{a}-1$, and the erosion risk level was severe. The average annual soil loss rate far exceeded the soil erosion threshold of $10 \mathrm{t} \cdot \mathrm{ha}-1 \cdot \mathrm{a}-1$, and it has intensified in recent years. It is believed that the ecological environment of Jilin Province will be unsustainable if this trend continues. 
(2) Distribution of soil erosion in Jilin Province: according to the average annual erosion rates of nine cities in Jilin Province, the results of ranking their soil erosion degrees from highest to lowest are as follows: Tonghua, Yanbian, Baishan, Jilin, Liaoyuan, Siping, Changchun, Songyuan and Baicheng. As the altitude decreases from east to west, the degree of soil erosion changes from strong to weak. In particular, the eastern mountainous areas of Jilin Province (including Tonghua, Yanbian, Baishan, Jilin and Liaoyuan) are dominated by strong erosion, and the Manchuan and Mangangtai areas in the central part and the western plain area (including Siping, Changchun, Songyuan and Baicheng) are dominated by very slight to slight erosion risk levels.

(3) The slope angle of $15^{\circ}$ was established as the critical threshold for sloped farmland in Jilin Province. The RUSLE model is mainly restricted by 5 factors, but the role of each factor in different geographic units is often quite different. Jilin Province of China is obviously affected by topographical factors. Based on the segmented S-slope factor model, from the perspective of the slope angle $\theta$, the soil erosion rate, soil erosion risk grade, soil erosion area, and total amount of soil erosion in Jilin Province were analysed with increasing a slope angle $\theta$. The study found that the slope angle of $15^{\circ}$ is the threshold for sloped farmland. It is proposed that the slope angle of sloped farmland in Jilin Province should not exceed $15^{\circ}$. An opinion is given that the slope angle $\theta \geq 15^{\circ}(10.1 \times 104$ ha) of steeply sloped farmland needs to implement the "returning farmland to forest and grassland" plan. For slope angles of $0^{\circ} \leq \theta \leq 5^{\circ}(674.95 \times 104 \mathrm{ha})$, which represents gently sloped farmland, and $5^{\circ} \leq \theta \leq$ $15^{\circ}(79.14 \times 104 \mathrm{ha})$, which represents sloped farmland, it is necessary to use scientific farming management methods to improve soil quality to prevent further land degradation.

(4) Key land types for soil erosion control in Jilin Province were proposed: Among the six land types, forestland experiences the most serious soil erosion, with a soil erosion rate as high as 84.12 $\mathrm{t} \cdot \mathrm{ha}^{-1} \cdot \mathrm{a}^{-1}$, which is a very strong soil erosion level. The second is agricultural land. Although the soil erosion rate is not high, approximately $12.39 \mathrm{t}^{\mathrm{t}} \cdot \mathrm{ha}^{-1} \cdot \mathrm{a}^{-1}$, which is classified as a moderate erosion level, is affected, and this is a large area; furthermore, the total amount of soil erosion is large, and its damage cannot be ignored. In general, managing these two types of land use should be the priority for soil erosion control in Jilin Province.

(5) The rainfall erosivity (R) factor was obtained based on CMORPH data: In this study, CMORPH radar data were used to successfully obtain the rainfall erosivity $(R)$ factor. This method better compensates for the defects of insufficient and uneven distribution of ground station data in larger areas. The results of this research further prove that the combination of the RUSLE model with RS data and GIS technology successfully quantitatively evaluates soil erosion. As a fast, convenient, and regional soil erosion monitoring method, this method has large social and economic benefits in the global environmental protection of land ecology.

Author Contributions: Conceptualization, Ping Zhou and Hong-Yuan Huo; methodology, Ping Zhou; software, Yue Jiang, Yanan Xie, Guangyuan Wei; validation, Zhiwen Si and Hainan Yang; formal analysis, Guangyuan Wei; investigation, Ping Zhou, Yue Jiang, and Yanan Xie; resources, Ping Zhou; data curation, Ping Zhou; writing-original draft preparation, Ping Zhou and Hong-Yuan Huo; writing-review and editing, Hong-Yuan Huo; supervision, Ping Zhou, Junchuan Yu and Hong-Yuan Huo; project administration, Ping Zhou and Junchuan Yu. All authors have read and agreed to the published version of the manuscript.

Funding: This research was funded by Natural Science of Foundation, grant number 41701425, and by Major Projects of High-resolution Earth Observation System (04-Y30B01-9001-18/20).

Acknowledgments: The research and writing of this paper have gone through more than 18 months. In this process, relevant research institutions and individual experts gave the author strong support and generous help. Professor Yuan Wanming from China University of Geosciences (Beijing), Professor Wang Runsheng from the Center for Aerial Geophysical Prospecting and Remote Sensing of the Ministry of Natural Resources of China, Professor Zhang Yuanfei from the Institute of Geology of China Nonferrous Metals Corporation, and Researcher Scientist Zhou Yong from the Institute of Geology and Geophysics of the Chinese Academy of Sciences, all discussed the topic and related issues in the study, and provided valuable guidance.

Conflicts of Interest: The authors declare no conflict of interest.

\section{References}


1. Belyaev V. R., Wallbrink P. J., Golosov V. N. et al. A comparison of methods for evaluating soil redistribution in the severely eroded Stavropol region, southern European Russia. Geomorphology. 2005,65(3), 173-193.

2. Singer M. J., Warkentin B. P., Soils in an environmental context: An American perspective. Catena, 1996, 27(3),179-189.

3. Sun Wenyi, Shao Quanqin, Liu Jiyuan, Soil erosion and its response to the changes of precipitation and vegetation cover on the Loess Plateau. J. Geogr. 2013, Sci. 2013, 23(6), 1091-1106.

4. Sharda VN; Mandal D, Ojasvi P. R. Identification of soil erosion risk areas for conservation planning in different states of India. J. Environ. Biol. 2013,34(2), 219-226.

5. Zakerinejad R, Maerker M. An integrated assessment of soil erosion dynamics with special emphasis on gully erosion in the Mazayjan basin, southwestern Iran. Nat. Hazards. 2015, 79(S1), 25-50.

6. Gayen A., Saha S. Application of weights-of-evidence (WoE) and evidential belief function (EBF) models for the delineation of soil erosion vulnerable zones: a study on Pathro river basin, Jharkhand, India. Model Earth Syst Environ. 2017, 3(3), 1123-1139.

7. David Pimentel N. K. Ecology of soil erosion in ecosystems. Ecosystems (1), 1998, pp. 416-426.

8. WANG Zhanli. Analyses of Affecting of Soil Erosion and Its Harms in China. Transactions of the CSAE.2000, 16(4), 32-35.

9. Lal R. Water management in various crop production systems related to soil tillage. Soil Tillage Res. 1994, 30, 169-185.

10. Tagil, S. Land degradation risk assessment for Tuzla Creek Basin (Biga Peninsula) using a GIS Based RUSLE Model. Ekoloji. 2007, 17 (65), 11-20.

11. S.D. Angima; D.E. Stott. Soil erosion prediction using RUSLE for central Kenyan highland conditions. Agriculture, Ecosystems and Environment 97. 2003, 295-308.

12. Wischmeier, W. H.; D. D. Smith; Uhland, R. E. Evaluation of factor in the loss equation. Agric. Eng. 1958, $39,458-462,474$.

13. Wischmeier W H; Smith D D. Predicting rainfall-erosion losses from cropland east of Rocky Mountains. USDA Agricultural Handbook. 1965.

14. Wischmeier W H; Smith D D. Predicting rainfall erosion losses: A guide to conservation planning. USDA: Handbook, 1978.

15. Renard K G, Foster G R, Weesies G A., et al. RUSLE: revised universal soil loss equation. Journal of Soil $\mathcal{E}$ Water Conservation, 1991, 46(1), 30-33.

16. Renard, K.G., Foster, G.R., Weesies, G.A., McCool, D.K., Yoder, D.C. Predicting soil erosion by water-a guide to conservation planning with the Revised Universal Soil Loss Equation (RUSLE). United States Department of Agriculture, Agricultural Research Service (USDA-ARS) Handbook No. 703. United States Government Printing Office, Washington, D.C.1997.

17. Youe-Qing X; Xiao-Mei S; Xiang-Bin K; Jian P; Yun-Long C. Adapting the RUSLE and GIS to model soil erosion risk in a mountainous karst watershed, Guizhou Province, China. Environ. Monit. Assess. 2008, 141(1-3), 275-286.

18. Nearing M.A.; Foster G.R.; Lane L.J.; Finkner S. C. A process-based soil erosion model for USDA-water erosion prediction project technology. 1989, T ASAE 32(5), 1587-1593.

19. Morgan R.P.C;Quinton J.N.; Smith R.E.; Govers G.;Poesen J.W.A.; Auerswald K.; Chisci G.; Torri D.; Styczen M.E. The European soil erosion model (EUROSEM): a dynamic approach for predicting sediment transport from fields and small catchments. Earth Surf. Proc. Land. 1998, 23,527-544.

20. Perović V., Životić L., Kadović R., Đorđević A., Jaramaz D., Mrvić V. \& Todorovic M., Spatial modeling of soil erosion potential in a mountainous watershed of south-eastern Serbia. Environ Earth Sci., 2012. 68: 115128.

21. Foster, G.R.Modeling the Erosion Process. In: Haan, C.T., Johnson, H.P. and Brakensiek, D.L., Eds., Hydrologic Modeling of Small Watersheds, ASAE Monograph No. 5, American Society of Agricultural Engineers, St. Joseph .1982, 297-380.

22. Renard, K. G.; G. R. Foster; G. A. Weesies; D. K. McCool; D. C. Yoder (Coordinators). Predicting Soil Erosion by Water: Guide to Conservation Planning with the Revised Universal Soil Loss Equation (RUSLE). U.S. Department of Agriculture, Agriculture Handbook No. 703 (In Review). 1995.

23. S.D. Angima; D.E. Stott; M.K. O’Neill; C.K. Ong; G.A. Weesies. Soil erosion prediction using RUSLE for central Kenyan highland conditions. Agriculture, Ecosystems and Environment 97 .2003, 295-308. 
24. Foster,G.R.; W.H. Wischmeier. Evaluating irregular slopes for soil loss prediction. Trans. ASAE. 1974,17,305-309.

25. Foster,G.R.; L.D. Meyer; C. A. Onstad. A run off erosivity factor and variable slope length exponents for soil loss estimates. Trans. ASAE. 1977, 20, 683-687.

26. Panos Panagos; Pasquale Borrelli; Katrin Meusburger; et al. Estimating the soil erosion cover-management factor at the European scale. Land Use Policy 48, 2015, 38-50.

27. Foster,G.R.; and R.E. Highfill. Effect of terraces on soil loss: USLE P-factor values for terraces. J. Soil Water Conserv. 1983, 38, 48-51.

28. Hong Huasheng; Yang Yuan; Huang Jinliang. Prediction of soil erosion at small watershed level based on GIS and Universal Soil Loss Equation (USLE). Journal of Xiamen University (Natural Science). 2005, 44(5), 675679.

29. Amiri, F.; and Tabatabaie, T.EPM Approach for Erosion Modeling by using RS and GIS, FIG Regional Conference on Spatial Data Serving People: Land Governance and the Environment -Building the Capacity Hanoi, Vietnam, 19-22 October,10p (2009).

30. Noori H; Karami H; Farzin S; et al. Investigation of RS and GIS techniques on MPSIAC model to estimate soil erosion. Natural Hazards. 2018, 91(1),221-238.

31. Weilin K. Research on Soil Erosion Based on the USLE Model and RS/GIS in the Dianchi Lake Watershed. Research of Soil and Water Conservation. 2012.

32. Tung Gia Pham; Jan Degener; Martin Kappas. Integrated universal soil loss equation (USLE) and Geographical Information System (GIS) for soil erosion estimation in A Sap basin: Central Vietnam. International Soil and Water Conservation Research. 2018, 6(2).

33. Z.Y. Shen; Y.W. Gong; Y.H. Li; Q. Hong; L. Xu; R.M. Liu. A comparison of WEPP and SWAT for modeling soil erosion of the Zhangjiachong Watershed in the Three Gorges Reservoir Area. Agricultural Water Management. 2009, 96(10).

34. Behera, P.; Durga Rao; K.H.V.; Das, K.K. Soil erosion modeling using MMF model -A remote sensing and GIS perspective. J Indian Soc Remote Sens 33, 165-176 (2005).

35. Roo, Ad; A.P.J.; Wesseling, C.G.; Jetten, V.G.; Ritsema, Coen. LISEM. A physically-based hydrological and soil erosion model incorporated in a GIS. In: K. Kovar \& H.P. Nachtnebel (eds.), Application of geographic information systems in hydrology and water resources management. Wallingford (UK), IAHS, 1996. IAHS Publ. 235, pp. 395-403.

36. Tahiri, M.; Tabyaoui, H.; Tahiri, A.; Hadi, H.; Hammichi, F.; Achab, M. Modelling Soil Erosion and Sedimentation in the Oued Haricha Sub-Basin (Tahaddart Watershed, Western Rif, Morocco): Risk Assessment. Journal of Geoscience and Environment Protection. 2016, 4, 107-119.

37. Mati, B.; Morgan, RPC; Quinton, John; Brewer, T.; Liniger; Hanspeter. Assessment of erosion hazard with the USLE and GIS: A case study of the Upper Ewaso Ng'iro North basin of Kenya. International Journal of Applied Earth Observations and Geoinformation. 2000,2, 78-86.

38. Cuomo, S; Della Sala, M; Pierri, M. Physically-based modeling of runoff and soil erosion in slopes with mountain tracks. Ebook, From Fundamentals to Applications in Geotechnics. IOS Press, 2015, 3143-3150.

39. Lu, D.; Li, G.; Valladares, G. S.; Batistella, M. Mapping Soil Erosion Risk in Rondo-nia, Brazilian Amazonia: using RUSLE, Remote Sensing and GIS. Land Degradation and Development, pp 499-512 (2004).

40. Lee, G.S.; Lee, K.H. Scaling effect for estimating soil loss in the RUSLE model using remotely sensed geospatial data in Korea. Journal of Hydrology and Earth System Sciences.2006, 3, 135-157.

41. Nasir, A.; Uchida, K.; Ashraf, M. Estimation of Soil Erosion by using RUSLE and GIS for Small Mountainous Watersheds in Pakistan. Pakistan Journal of Water Resources, Vol.10 (1), pp 11-21 (2006).

42. Ismail, J.;S. Ravichandran.RUSLE2 Model Application For Soil Erosion Assessment Using Remote Sensing and GIS. Water Resour. Manage. 2008, 22,83-102.

43. Ozsoy, G.; Aksoy, E.; Dirim, M.S.; Tumsavas, Z. Determination of Soil Erosion Risk in the Mustafakemalpasa River Basin, Turkey, Using the Revised Universal Soil Loss Equation, Geographic Information System, and Remote Sensing. Environmental Management, Issue 4, Volume 50, pp 679-694 (2012).

44. Mallick J; Alashker Y; Mohammad SA; Ahmed M; Hasan MA. Risk assessment of soil erosion in semi-arid mountainous watershed in Saudi Arabia by RUSLE model coupled with remote sensing and GIS. Geocarto Int. 2014,29,915-940. 
45. Yahya Farhan; Dalal Zregat; Ibrahim Farha. Spatial Estimation of Soil Erosion Risk Using RUSLE Approach, RS, and GIS Techniques: A Case Study of Kufranja Watershed, Northern Jordan. Journal of Water Resource and Protection. 2013, 5, 1247-1261.

46. Thlakma S.R.; Iguisi E.O.; Odunze A.C.; Jeb D.N. Estimation of Soil Erosion Risk in Mubi South Watershed, Adamawa State, Nigeria. J Remote Sensing \& GIS .2018,7, 226.

47. http://www.moa.gov.cn/gk/tzgg_1/tz/202003/t20200318_6339304.htm

48. Jianjun Tang. China Encyclopedia Atlas, 2012, ISBN, 9787503160868, Sinomap Press.

49. Lei, X. U., Qiao ZHANG, Jing ZHANG, Z. H. A. O. Liang, S. U. N. Wei, and Yun-xiang JIN. "Extreme meteorological disaster effects on grain production in Jilin Province, China." Journal of integrative agriculture 16, no. 2 (2017): 486-496.

50. Fan, ChunNan, ShiJie Han, ZhongLing Guo, JinPing Zheng, and Yan Cheng. "Present status and rate of carbon sequestration of forest vegetation in Jilin Province, Northeast China." Chinese Journal of Plant Ecology 40, no. 4 (2016): 341-353.

51. Brown, L.C.; Foster, G.R. Storm erosivity using idealized intensity distributions. Trans. ASAE. 1987,30, 379386.

52. Zhang X K; Xu J H; et al. Study on the equation of soil loss in Heilongjiang Province. Soil and Water Conservation Bulletin. 1992, 18(4),1-9.

53. Wischmeier W. H.; Smith D. D. Rainfall energy and Its relationship to soil loss. Transactions, American Geophysical Union.1958,39,285-291.

54. Foster G R. Evaluation of Rainfall-Runoff Erosivity factors for individual storm. Transactions of the ASABE.1982,25(1),124-129.

55. United States Department of Agriculture. EPIC-Erosion/Productivity Impact Calculator 1 Model Documentation Technical Bdletin Number 1768R. Washington DC: USDA-ARS.1990.

56. Ferraro, R. R.SSM/I derived global rainfall estimates for climatological applications. J. Geophys. Res. 1997, 102, 16 715-16 735 .

57. Ferraro, R. R.; F. Weng; N. C. Grody; L. Zhao. Precipitation characteristics over land from the NOAA-15 AMSU sensor. Geophys. Res. Lett. 2000, 27,2669-2672.

58. Ferraro, R. R.; Q. Li. Detailed analysis of the error associated with the rainfall retrieved by the NOAA/NESDIS/SSMI algorithm: II. Rainfall over land. J. Geophys. Res. 2002,107, 4680-4686.

59. Tesfay G. Gebremicael; Yasir A. Mohamed; et al. Comparison and validation of eight satellite rainfall products over the 2 rugged topography of Tekeze-Atbara Basin at different spatial and temporal scales. 2017.

60. Jie Liu; Jun Xia; et al. "Evaluation of Six Satellite-Based Precipitation Products and Their Ability for Capturing Characteristics of Extreme Precipitation Events over a Climate Transition Area in China", Remote Sensing. 2019.

61. Huffman, G. J.; R. F. Adler; E. F. Stocker; D. T. Bolvin; E. J. Nelkin. Analysis of TRMM 3-hourly multisatellite precipitation estimates computed in both real and post-real time. Preprints, 12th Conf. on Satellite Meteorology and Oceanography, Long Beach, CA, Amer. Meteor. Soc., CD-ROM, P4.11,2003.

62. Robert J. Joyce; John E. J; et al. CMORPH: A Method that Produces Global Precipitation Estimates from Passive Microwave and Infrared Data at High Spatial and Temporal Resolution, Journal of Hydrometeorology, vol. 5, no. 6, pp. 487-503, 2004.

63. R. J. Joyce; P. Xie; Y. Yarosh; J. E. Janowiak; P. A Arkin. “CMORPH: a "morphing” approach for high resolution precipitation product generation," in Satellite Rainfall Applications for Surface Hydrology, M. Gebremichael and F. Hossain, Eds., pp. 23-37, Springer, Netherlands, 2010.

64. E. Habib; A. T. Haile; Y. Tian; R. J. Joyce. "Evaluation of the high-resolution CMORPH satellite rainfall product using dense rain gauge observations and radar-based estimates," Journal of Hydrometeorology, vol. 13, no. 6, pp. 1784-1798, 2012.

65. Augusto Jose'; Pereira Filh; Felipe Vemado; et al. "A Step towards Integrating CMORPH Precipitation Estimation with Rain Gauge Measurements".2018.

66. El-Swaify, S.A.; Dangler, E.W. Erodibilities of selected tropical soils in relation to structural and hydrologic parameters. In: Foster, G.R. (Ed.), Soil Erosion Prediction and Control. Soil and Water Conservation Society, Ankeny, IA, USA,.1976, pp. 105-114.

67. Williams J R; Dyke P T; Fuchs W W; et al. EPIC: Erosion Productivity Impact Calculator: Users Manual//Sharpley A N, Williams J R. (Eds.). EPIC: Erosion Productivity Impact Calculator, Model 
Documentation, USDA-ARS Tech. Bull. No. 1768, USDA-ARS Grassland, Soil and Water Research Laboratory, Temple, TX, 1990,127.

68. Wischmeier W H.; Mannering J V. Relation of soil properties to its erodibility. Soil Sci. Am. Proc.1969, 33, 131-137.

69. Wischmeier W H; Smith D D. Prediction Rainfall Erosion Losses. Washington D C: USDA.1987.

70. MeCool D K; Brown L C; Foster G R; et al. Revised slope steepness factor for the universal soil loss equation. TRANSACTIONS of the ASAE.1987,30(5),1387-1396.

71. Liu B Y; Nearing M A; Rise L M. Slope gradient effects on soil loss for steep slopes. Transactions of the ASAE.1994,37,1835-1840.

72. Liu BY; Zhang KL; Xie Y. An empirical soil loss equation. Proceedings-Process of soil erosion and its environment effect.12th international Soil conservation organization conference, Tsinghua University Press.Beijing.2002,21-25.

73. Alaa M; Atiaa AL-ABADI; Hussein B. GHALIB; et al. Estimation of soil erosion in northern Kirkuk Governorate, Iraq using RUSLE, Remote Sensing and GIS", Carpathian Journal of Earth and Environmental Sciences, February 2016, Vol. 11, No. 1, p. 153-166.

74. Cai C F; Ding S W; Shi Z H; et al. Study of applying USLE and geographical information system IDRISI to predict soil erosion in small watershed. Journal of Soil and Water Conservation. 2000,14(2),19-24. (in Chinese).

75. Zhang Xiankui. Brief Introduction to Application of Soil Loss Equation in Heilongiiang Province. Journal of Land and Natural Resources Research, 1995(1): 30-32.

76. Singh G; Ram B; Narain P; Bhusan LS; Abrol IP. Soil erosion rates in India, Journal of Soil and Water Conservation.1992,47(1),97-99.

77. J. Sanchez L.; Recatala J.C.; Colomer C. Aiio. Assessment of soil erosion at national level: a comparative analysis for Spain using several existing maps, Transactions on Ecology and the Environment 2001, vol 46, ISSN 1743-3541.

78. Morgan RPC. 1995. Soil erosion and conservation. 2nd ed. Essex: Longman. Oldeman LR. 2000. Impact of soil degradation: a global scenario. Wageningen. Netherlands: International Soil Reference and Information Centre; p. 1-11.

79. Qian Zhengying. Strategic Concern to Land and Water Resources Allocation, Ecology and Environment Protection and Sustainable Development of Northeast China. ENGINEERING SCIENCE, 2006(8): 1-24

80. Laura Schmitt Olabisi. Uncovering the Root Causes of Soil Erosion in the Philippines, Society and Natural Resources.2012,25,37-51.

81. LIU Hui-qing; NIAN Ji-gang; ZHAO Lan-po. Remote Sensing Investigation and Analysis of Soil and Water Losses in Jilin Province. JOURNAL OF JILIN AGRICULTURAL UNIVERSITY, 2008, 30(3): 328-333.

82. Zhang Yongxin. The Analysis of Current Situation And The Countermeasure Of Soil Erosion OF Jilin Province, Master Thesis, 2004. cdmd.cnki.com.cn/article/cdmd-10183-2. 